Fixed Point Theory, 21(2020), No. 1, 319-338

DOI: $10.24193 /$ fpt-ro.2020.1.23

http://www.math.ubbcluj.ro/ nodeacj/sfptcj.html

\title{
ON $\psi$-CONTRACTIONS AND COMMON FIXED POINT RESULTS IN PROBABILISTIC METRIC SPACES
}

\author{
JINGFENG TIAN*, XIMEI HU** AND DONAL O'REGAN*** \\ *Department of Mathematics and Physics, North China Electric Power University, \\ Baoding, Hebei Province, 071003, China \\ E-mail: tianjf@ncepu.edu.cn \\ ${ }^{* *}$ China Mobile Group Hebei Co., Ltd., Baoding, Hebei Province, 071051, China \\ E-mail: huxm_bd@163.com \\ ***School of Mathematics, Statistics and Applied Mathematics, \\ National University of Ireland, Galway, Ireland \\ E-mail: donal.oregan@nuigalway.ie
}

\begin{abstract}
In this paper, by weakening the conditions on the gauge function $\psi$, some new fixed point and common fixed point (common coupled fixed point, common tripled fixed point) theorems for nonlinear mappings with a gauge function $\psi$ in Menger probabilistic metric spaces are established. An example is given to illustrate our theory.

Key Words and Phrases: Coupled fixed point, fixed point, metric space, probabilistic $\varphi$ contractions, gauge function.
\end{abstract}

2010 Mathematics Subject Classification: 54E70, 54H25, 47H10.

Acknowledgements. The authors would like to thank the anonymous referees.

This work was supported by the Fundamental Research Funds for the Central Universities (No. 2015ZD29) and the Higher School Science Research Funds of Hebei Province of China (No. Z2015137).

\section{REFERENCES}

[1] M. Abbas, M. Ali Khan, S. Radenović, Common coupled fixed point theorems in cone metric spaces for w-compatible mappings, Appl. Math. Comput., 217(2010), 195-202.

[2] A. Aghajani, N. Sabzali, Existence of coupled fixed points via measure of noncompactness and applications, J. Nonlinear Convex Anal., 15 (2014), no. 5, 941-952.

[3] M.S. Asgari, B. Mousavi, Coupled fixed point theorems with respect to binary relations in metric spaces, J. Nonlinear Sci. Appl., 8(2015), 153-162.

[4] T.G. Bhashkar, V. Lakshmikantham, Fixed point theorems in partially ordered metric spaces and applications, Nonlinear Anal., 65(2006), 1379-1393.

[5] V. Berinde, M. Borcut, Tripled fixed point theorems for contractive type mappings in partially ordered metric spaces, Nonlinear Anal., 74(2011), no. 15, 4889-4897.

[6] M. Borcut, V. Berinde, Tripled coincidence theorems for contractive type mappings in partially ordered metric spaces, Appl. Math. Comput., 218(2012), 5929-5936. 
[7] S.S. Chang, Y.J. Cho, S.M. Kang, Nonlinear Operator Theory in Probabilistic Metric Spaces, Nova Science Publisher, New York, 2001.

[8] L. Ćirić, Solving the Banach fixed point principle for nonlinear contractions in probabilistic metric spaces, Nonlinear Anal., 72(2010), 2009-2018.

[9] D. Dorić, Nonlinear coupled coincidence and coupled fixed point theorems for not necessary commutative contractive mappings in partially ordered probabilistic metric spaces, Appl. Math. Comput., 219(2013), no. 11, 5926-5935.

[10] J.X. Fang, Common fixed point theorems of compatible and weakly compatible maps in Menger spaces, Nonlinear Anal., 71(2009), 1833-1843.

[11] O. Hadžić, Fixed point theorems for multivalued mappings in probabilistic metric spaces, Fuzzy Sets Systems, 88(1997), 219-226.

[12] O. Hadžić, E. Pap, Fixed Point Theory in Probabilistic Metric Spaces. Mathematics and Its Application, Vol. 536, Kluwer Academic, Dordrecht, 2001.

[13] J. Harjani, B. López, K. Sadarangani, Fixed point theorems for cyclic $\varphi$-contractions in ordered metric spaces, Fixed Point Theory, 14(2013), no. 2, 359-368.

[14] J. Jachymski, On probabilistic $\varphi$-contractions on Menger spaces, Nonlinear Anal., 73(2010), 2199-2203.

[15] W.A. Kirk, B. Sims, Handbook of Metric Fixed Point Theory, Kluwer Academic Publishers, 2001.

[16] V. Lakshmikantham, L.B. Ćirić, Coupled fixed point theorems for nonlinear contractions in partially ordered metric spaces, Nonlinear Anal., 70(2009), 4341-4349.

[17] T. Luo, C. Zhu, Z. Wu, Tripled common fixed point theorems under probabilistic $\varphi$-contractive conditions in generalized Menger probabilistic metric spaces, Fixed Point Theory Appl., 2014(2014), 158.

[18] N. Malhotra, B. Bansal, Some common coupled fixed point theorems for generalized contraction in b-metric spaces, J. Nonlinear Sci. Appl., 8(2015), 8-16.

[19] K. Menger, Statistical metrics, Proc. Natl. Acad. Sci. USA, 28(1942), 535-537.

[20] D. O'Regan, R. Saadati, Nonlinear contraction theorems in probabilistic spaces, Appl. Math. Comput., 195(2008), 86-93.

[21] B. Przebieracz, An application of the common fixed point theorems to the theory of stability of functional equations, Fixed Point Theory, 16(2015), no. 1, 185-190.

[22] S. Radenović, A note on tripled coincidence and tripled common fixed point theorems in partially ordered metric spaces, Appl. Math. Comput., 236(2014), 367-372.

[23] B. Schweizer, A. Sklar, Probabilistic Metric Spaces, Elsevier, New York, 1983.

[24] S. Sedghi, I. Altun, N. Shobe, Coupled fixed point theorems for contractions in fuzzy metric spaces, Nonlinear Anal., 72(2010), 1298-1304.

[25] V.M. Sehgal, A.T. Bharucha-Reid, Fixed points of contraction mappings on PM-spaces, Math. Syst. Theory, 6(1972), 97-100.

[26] Sh. Wang, S.M. Alsulami, L. Ćirić, Common fixed point theorems for nonlinear contractive mappings in fuzzy metric spaces, Fixed Point Theory Appl., 2013(2013), 191.

[27] J.-Z. Xiao, X.-H. Zhu, Y.F. Cao, Common coupled fixed point results for probabilistic $\varphi$ contractions in Menger spaces, Nonlinear Anal., 74(2011), 4589-4600.

Received: September 12, 2017; Accepted: January 11, 2018. 
